\title{
FREE RADICAL REACTIONS IN BIOLOGICAL SYSTEMS - A CONCEPT APPROACHED IN THE RESEARCHES CARRIED OUT BY PROFESSOR CRISTOFOR I. SIMIONESCU
}

\author{
VALENTIN I. POPA \\ “Gheorghe Asachi” Technical University of Iasi, Iasi, Romania \\ ¿Corresponding author: vipopa@tuiasi.ro
}

This paper is dedicated to Professor Cristofor I. Simionescu to remind us of the esteem in which this man is held worldwide and of the vibrancy of current research in wood science

\begin{abstract}
Between 1956 and 1968, professor Cristofor I. Simionescu, together with his coworkers, carried out extensive research in the field of vegetable tumor. They studied different aspects of the induction, evolution, chemistry and inhibition of crown gall disease (the formation of tumor) caused by Agrobacterium tumefaciens (Rhizobium radiobacter). To inhibit tumor formation, polyphenol compounds were used, supposing their action to be based on the inhibition of radicals involved in cancer propagation. At present, the activity of natural polyphenols has been confirmed by a considerable body of published research. Continuing the preoccupations of professor Simionescu and based on the biorefining principle, we have separated and characterized natural polyphenols from different sources, and their activity was demonstrated in different biological systems.
\end{abstract}

Keywords: Agrobacter tumefaciens, crown gall, free radicals, polyphenols, antibacterial, antioxidants

\section{INTRODUCTION}

Agrobacter tumefaciens (synonyms:

Bacterium tumefaciens, Rhizobium radiobacter) naturally infects wound sites in dicotyledonous plants, causing the formation of crown gall tumors. The first evidence, indicating this bacterium as the causative agent of the crown gall, goes back to more than a hundred years ago. ${ }^{1}$ Since then, for different reasons, a large number of research works have focused on the study of this neoplastic disease and its causative pathogen. This soil-borne bacterium enters the roots of the host plant through wounds caused by planting, cultivation, frost heaving, insects or nematodes. Upon attaching to the plant cell walls, the bacterium transfers parts of plasmid DNA to the plant. The Ti plasmid causes the plant's cells to multiply rapidly without going through apoptosis, resulting in tumor formation, which is similar in nucleic acid and histology to human and animal cancers. The T-DNA has also been transferred to human cells, demonstrating the diversity of insertion application. Affected cells begin to multiply at an uncontrolled rate, resulting in visible tumors within 2-4 weeks. The mechanisms by which Agrobacterium inserts materials into human cells, by the type IV system, is very similar to the mechanisms used by animal pathogens to insert materials (usually proteins) into human cells - also a type IV secretion. More than 600 plants are susceptible to crown gall. During the first and extensive period, scientific efforts have been devoted to disclosing the mechanisms of crown gall tumor induction, hoping to understand the mechanisms of oncogenesis in general, and to eventually apply this knowledge for developing drug treatments for cancer disease in animals and humans. This makes Agrobacterium an important topic of medical research as well. Besides, it plays a vital role in various aspects of antitumor studies.

Antioxidants (AOX) are considered a promising therapeutic approach, as they may be playing neuroprotective (preventing apoptosis) and neurodegenerative roles. The main characteristic of an antioxidant is its ability to trap free radicals. In nature, AOX are grouped as 
exogenous and endogenous. The endogenous group includes enzymes (and their component trace elements), such as superoxidase dismutase $(\mathrm{Zn}, \mathrm{Mn}$ and $\mathrm{Cu})$, glutathione peroxide (Se) and catalase, as well as proteins, such as albumin, transferrin, ceruloplasmin, metallothionein and haptoglobin. The most important exogenous AOX are dietary phytochemicals (such as polyphenols, quinones, flavonoids, catechins, coumarins, terpenoids) and the smaller molecules, such as ascorbic acid (Vitamin C), alpha-tocopherol (Vitamin E) and beta-carotene Vitamin E, and supplements. The antioxidant processes occur in cytosol, mitochondria or in plasma. ${ }^{2}$

Many plant extracts and phytochemicals have been shown to have free radical scavenging properties, but generally, there is still a need to find out more information concerning the antioxidant potential of plant species. Moreover, the antitumor activities of plant extracts have been also determined using Agrobacterium tumefaciens in carrot-disc assays. ${ }^{3-6}$

Between 1956 and 1968, professor Simionescu and his coworkers carried out studies concerning the induction, ${ }^{7-10}$ evolution, chemistry ${ }^{11-16}$ and inhibition $^{17-21}$ of tumors determined by the infection of different plant species with Bacterium tumefaciens. Following plant infection, an important chemical modification was observed. ${ }^{17}$ Thus, a lignification process took place to defend the plant against pathogen invasion. If the content of lignin in normal tissue is $26.74 \%$, it increased in the tumor up to $37.29 \%$, while the cellulose content decreased from 43.14 to $37.77 \%$.

It is known that lignin is biosynthesized by radical reactions starting from coniferyl alcohol or its derivatives, a reaction that is initiated by laccase. The interaction of the resulted radicals leads to the formation of dimmers, trimmers and finally of lignin. ${ }^{22}$ This reaction has some interesting practical applications, such as in the synthesis of lignin grafted with synthetic polymers, polymerization of lignin fragments with low molecular mass, which can be used in waste water treatment or for sequestration of pollutants in the soil, and to create adhesives for binding wood fibers using lignin and laccase or peroxidases.

In their studies, Simionescu et al. have proposed and demonstrated that the formation of radicals during this biosynthesis process could be inhibited using antioxidants, such as hydroquinone, gallic acid and its derivatives (propyl-, ethyl- octyl- and dodecyl gallate), butylhydroxyanisol and nordihydroguaiaretic acid. These results were obtained for Solanum lycopersicum infected by crown gall tumor.

Interestingly, at the same time, Denham Harman proposed The free radical theory of aging published in $1956 .^{23}$ He proposed that free oxygen radicals produced in the body cause aging, and further stated that "reducing compounds" (what we would now call "antioxidants") might represent a "chemical means of prolonging effective life" and that these molecules "might be of benefit in the field of cancer chemotherapy and nutrition". At present, there is a lot of information regarding the role of natural compounds, such as polyphenols, which are tested in vitro and in vivo (animal, human, vegetable systems or microorganisms) to demonstrate their antioxidant properties. $^{24,25}$

Starting from the results obtained by Simionescu et al. and the research literature published in the field of antioxidants, we undertook studies in the field of polyphenols. As known, they are secondary metabolites biosynthesized by plants. There are more than 8000 polyphenolic compounds identified, from which 4000 are flavonoids. For the polyphenols, the following properties were identified: antioxidant, prooxidant, anticancer agents, apoptosis-inducing, antibacterial, antiparasite, anti-HIV activities, amelioration of cardiovascular diseases, improvement of endothelial function, modulation of gamma-glutamylcysteine synthetase expression, improvement of health and survival on high fat diet, coloring agents, chelating agents, modulators of plant development.

\section{ISOLATION AND CHARACTERIZATION OF POLYPHENOLS}

The separation of polyphenols can be carried out using a technology of biorefining that was proposed by us $^{26,27}$ some years ago in a research project supervised by professor Simionescu (Fig. 1). The technology illustrated in Figure 1 allows separating the secondary and the main compounds of biomass, which can be used in different fields due to their biological activities. ${ }^{28,29}$

In our studies, for isolating polyphenols, we used wastes resulting from different industrial processes, as well as spontaneous and cultivated plants, as raw materials. Some of the raw materials we used are described below.

Spruce bark (Picea abies) is an abundant byproduct resulting from the wood processing 
industry. Spruce and pine barks are known by their rich content of proanthocyanidins and they have been used in folk medicine and as a dietary supplement.

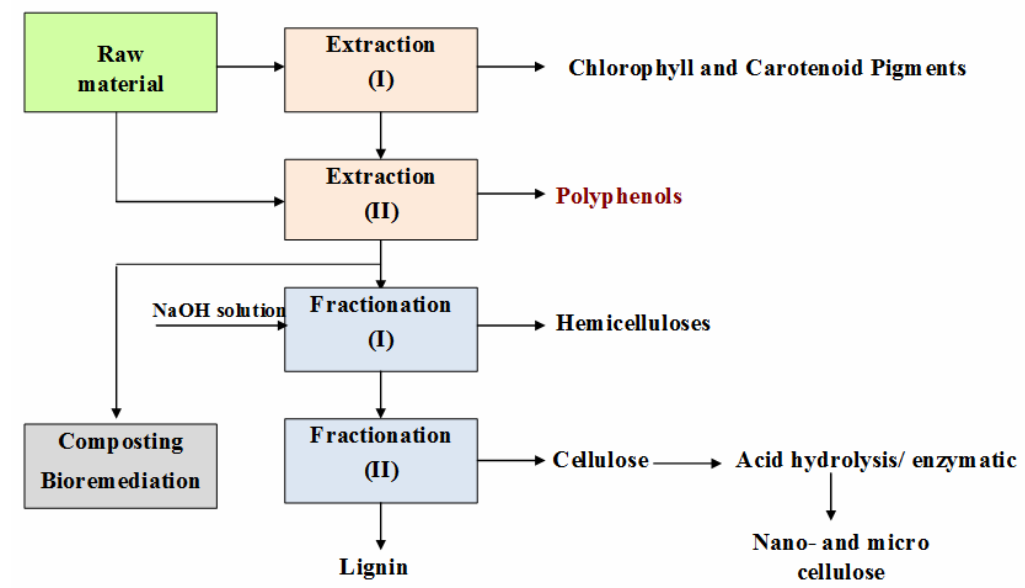

Figure 1: Separation of compounds with biological properties from biomass by biorefining

Grape seeds represent a considerable proportion of pomace, amounting to $40-50 \%$ on a dry matter. In recent years, naturally occurring plant phenolics in grape by-products have drawn a lot of interest, considering that grapes (Vitis vinifera) belong to the world's largest fruit crops. Grape seeds contain catechin, epicatechin, dimeric, trimeric and tetrameric proanthocyanidin, having antioxidant activity against reactive oxygen species (ROS). The grape seeds extract has proved helpful in various diseases, such as hepatic fibrosis, ischemiareperfusion injury (reducing the size of infarction in cardiac ischemia) and cancer. Also, it inhibits free radical production and has an important influence in the carbohydrate metabolism in fermentation and diabetes.

Hawthorn (Crategus monogyna) is a spontaneous plant known in traditional medicine for its many health benefits, especially in cardiovascular health.

Asclepias syriaca was selected and cultivated in our studies due to its energetic value, being rich in hydrocarbons. It is characterized by a complex composition comprising cellulose, hemicelluloses, lignin, polyphenols, sugars, alkaloids and hydrocarbons. It can be used as raw material to be processed by the biorefining technology proposed by us, allowing recovering all the compounds. ${ }^{26}$ At the same time, hydrocarbons and unsaturated fatty acids could be used as an alternative to obtain triglycerides and biofuel.

Lingonberry (Vaccinium myrtillus L.) is a wild shrub, whose fruits and aerial parts are used as food and in traditional medicine, due to their richness in bioactive phenolic compounds. Seasonal variations of the phenolic constituents in bilberry leaves, stems and fruits have been observed and characterized from the viewpoint of antioxidant properties.

The extraction of polyphenols can be performed using different techniques and solvents, which influence the composition and yields of the recovered compounds. Thus, the following techniques have been used: conventional Soxhlet extraction, ultrasounds, microwave and supercritical fluids assisted extractions. Water, methanol and ethanol have been used as extraction agents and their influence on the extracted total polyphenolic compounds (TPC) was determined by the Folin-Ciocalteu method. The content in phenolic compounds was correlated well with TPC and the 2,2-diphenyl-1picrylhydrazyl (DPPH) radical scavenging activity. The total phenolic content was expressed in $\mathrm{mg}$ gallic acid equivalents (GAE) per $\mathrm{g}$ dried extract (d.e.), using a standard curve of gallic acid (0.1-2.0 $\mu \mathrm{g} / \mathrm{mL})$. The information concerning the polyphenol compositions was enhanced when we used HPLC associated with mass spectroscopy. 
At the same time, after alkaline hydrolysis, other polyphenolic acids were identified, which proved that some of them are present in glycoside form.

\section{BIOLOGICAL PROPERTIES OF POLYPHENOLS}

Concerning polyphenols, in our research programs, the following directions have been undertaken: modulation agents of carbohydrates metabolism in diabetes and alcoholic fermentation, agents for regulation of physiological process in plants (germination, plant propagation and cultivation, tissue culture, bioremediation), modulation agents of metabolic processes in microorganisms (antifungal and antibacterial properties, antioxidants), models to study the influence of stress factors (hydrogen peroxide oxidation and UV irradiation and life span regulation), and carbon sources as substrates in medium cultivation of microorganisms. ${ }^{30-48}$

Polyphenols are large, complex molecules found almost exclusively in plant products. These molecules possess unique chemical characteristics, including the ability to powerfully scavenge reactive oxygen and nitrogen species, blocking oxidative damage that leads to inflammation and biological aging of tissue. Reactive oxygen species (ROS) and reactive nitrogen species (RNS), such as hydroxyl radical $(\bullet \mathrm{OH})$, hydrogen peroxide $\left(\mathrm{H}_{2} \mathrm{O}_{2}\right)$, superoxide $\left(\mathrm{O}_{2} \bullet-\right)$, nitric oxide $(\mathrm{NO} \bullet)$, peroxynitrite (ONOO-) and others are major sources of oxidative stress in cells, damaging proteins, lipids, and DNA. Oxidative DNA damage has been identified as a cause of cancer, aging and neurodegenerative diseases, such as Alzheimer's and Parkinson's, cardiovascular diseases, such as arteriosclerosis, and is the primary cause of cell death and tissue damage resulting from heart attack and stroke. Therefore, the prevention of oxidative stress caused by ROS and RNS has important implications for the prevention and treatment of diseases. LDL oxidation and platelet activation are two key events in atherogenesis, which lead to the formation of atherosclerotic lesion. These processes are interrelated, in that oxidized LDL can activate platelets, and activated platelets increase the susceptibility of LDL to oxidation. Atherosclerosis is associated with endothelial dysfunction, platelet activation, lipoprotein aggregation, macrophage foam cell formation, inflammation and thrombosis. These events are closely related and interact among themselves, finally leading to the formation of atherosclerotic lesions. Atherosclerosis involves both LDL oxidation and platelet formation and both processes can affect each other. Platelet activation is increased by oxidative stress, and oxidized LDL, in turn, was shown to enhance platelet activation. Activated platelets in turn can increase LDL oxidizability. ${ }^{49}$

Any means of intervention that favorably affects the balance between the activity of the macrophage oxygenases and cellular antioxidants, as well as the elevation of LDL associated antioxidants or extrinsic antioxidants in plasma or extracellular space, can possibly contribute to the inhibition of the atherosclerotic process. Strategies to reduce LDL oxidation thus involve the use of various antioxidants, which synergistically act on the cells and/or on the LDL molecules. In very simple terms, flavonoids inhibit the oxidation of polyunsaturated fatty acid groups in LDL by intercepting the free radical propagation of LDL oxidation.

However, polyphenols are more than just free radical scavengers. Depending on their specific type and source, they also potently modulate gene expression. It means that polyphenols with unique characteristics can be chosen to address specific disease processes. The common yeast Saccharomyces cerevisiae is often used in laboratory experiments as a model for understanding the biology of higher organisms due to the great similarity of basic life processes. The yeast is ideal in detecting cancerous chemicals, because its DNA-damage response system is remarkably similar to human cells. It can also be used to detect other types of damage, such as oxidative stress with a high degree of accuracy. Furthermore, the yeast cultures increased the expression of sirtuins, molecules known to trigger calorie restriction-like effects in multiple tissues, contributing to longevity. When polyphenols were added to yeast cell cultures, it was found that the treated cultures lived an average of 2.3 generations longer than the control cultures. Sirtuins are involved in a wide range of cellular processes, such as aging, transcription, apoptosis, inflammation and stress resistance, as well as energy efficiency and alertness during low-calorie situations. Sirtuins can also control circadian clocks and mitochondrial biogenesis. When yeast cultures were treated with polyphenols from grape seeds and spruce wood bark, it was observed that the treatment enhanced the cells' resistance to oxidative stress, both by 
inhibiting the production of harmful reactive oxygen species and by ramping up gene expression of vital natural cellular antioxidant systems. Thus, it was observed that polyphenols protect the yeast cell against hydrogen peroxide and UV irradiation and they can be used to inhibit cancer development.

Grape seeds are also appreciated due to their content of phenolic compounds, such as gallic acid, catechin and epicatechin, and a wide variety of procyanidins (mainly condensed tannin). Their biological activities include: antioxidant properties and radioprotective effects, prevention of cataract, antihyperglycemic effects, enhancement of postprandial lipemia, modulation of the expression of antioxidant enzyme systems, improvement of insulin sensitivity and prevention of hypertriglyceridemia, inhibition of aromatase and suppression of aromatase expression, inhibition of protein kinase activity of epidermal growth factor receptor, protective effects against oxidative damage in mouse brain cells and antiinflammatory effects. Oxidative stress is a condition arising from an imbalance between oxidant and antioxidants, leading to excess production of ROS. ROS are natural by-products of mithocondrial electron-transport chain reactions. The mithocondria are the "power plant" of the cell, generating chemical energy by producing adenosine triphosphate (ATP), the body's "energy currency".

When polyphenols are used as agents for regulation of physiological process in plants (germination, plant propagation and cultivation, tissue culture, bioremediation), they could have similar effects with auxine and citokinine, and their action is synergetic with that of the hormones biosynthesized by plants.

Polyphenolic extracts exhibited antibacterial properties against Staphylococcus aureus, Escherichia coli and Pseudomonas aeruginosa. The antimicrobial activity of the extracts against the tested microorganisms might be related to the presence of phenolic acids, such as gallic, protocatechuic, 3-hydroxybenzoic, chlorogenic acids and flavonoids, in the extracts. ${ }^{32}$

Electrospun poly(2-hydroxyethyl methacrylate) (pHEMA) fibers, loaded with synthetic and natural antioxidants in the form of selected types of polyphenols, such as vanillic, gallic, syringic acids, catechin or natural spruce bark extract, were investigated with regard to their release behavior in terms of antioxidant activities. $^{43}$
Another study reports on the development of poly(L-lactide-co-glycolide)

(PLGA) bicomponent fibers, loaded with selected amounts of the natural polyphenolic antioxidant catechin. The activity of the released catechin was assessed regarding its influence on multi-walled carbon nanotube (MWCNT) induced formation of reactive oxygen species (ROS) in the human alveolar epithelial cell line A549. As a proof of the concept, the activity of the released catechin in A549 cells stimulated with MWCNTs was determined, revealing a high reduction of ROS production in a dose dependent manner.

\section{CONCLUSION}

The antioxidant properties of polyphenols have been proposed by prof. Simionescu and his coworkers, who demonstrated their capacity to inhibit vegetal tumor development. Polyphenolic compounds, along with other bioactive compounds, can be obtained from secondary resources or from cultivated plants using biorefining. There are numerous polyphenols with different structures and compositions, depending on the raw material and the techniques used for their extraction. Polyphenols are characterized by many interesting properties (antioxidant, antifungal and antibacterial, preventing and inhibiting agents of cancer, protection agents of the vascular system), which recommend their utilization in different biological systems. The biological properties of polyphenols have been demonstrated using different model systems: plant, animal and human cells and microorganisms. Polyphenols can be immobilized by electrospinning or included in different supports (e.g. cyclodextrins) to be used in biological systems. The resulting products showed no loss of the antioxidant capacity and could be useful for tissue engineering applications.

\section{REFERENCES}

1 F. E. Smith and C. O. Towsend, Science, 25, 671 (1907), https://doi.org/10.1126/science.25.643.671

2 E. B. Kurutas, Nutr. J., 15, 71 (2015), https://doi.org/10.1186/s12937-016-0186-5

3 A. B. Galsky, J. P. Wilsey and R. G. Powellk, Plant Physiol., $\quad$ 65, $184 \quad$ (1980), https://doi.org/10.1104/pp.65.2.184

4 F. C. Chen, S. H. Hseu, S. T. Hung, M. C. Chen and C. Y. Lin, Bot. Bull. Acad. Sin., 40, 237 (1999), https://ejournal.sinica.edu.tw/bbas/content/1999/3/bot4 03-10.html 
5 A. C. Braun, Prog. Exp. Tumor Res., 15, 165 (1972), https://doi.org/10.1159/000392513

6 M. M. Mon, S. S. Maw and Z. K. Oo, Int. J. Biosci. Biochem. Bioinform., 1, $142 \quad$ (2011), https://doi.org/10.7763/IJBBB.2011.V1.26

7 Cr. I Simionescu, M. Grigoras, A. Cernatescu and S. Grigoras, Bul. Inst. Polit. Iasi, II(IV), Fasc. 1-2, 115 (1956)

8 Cr. Simionescu and M. Grigoras, Pap. Puu, 39, 283 (1957), http://www.paperjournal.fi

9 Cr. I. Simionescu, Bul. Inst. Polit. Iasi, Serie nouă, 5, 155 (1959)

${ }^{10}$ Cr. I. Simionescu, E. Calistru and N. Simionescu, Rev. Roum. Chim., 6, $235 \quad$ (1961), http://revroum.lew.ro

11 Cr. I. Simionescu and M. Grigoraş, St. Cercet. Şt. Chim., 7, 145 (1956)

12 Cr. I. Simionescu, Bul. Inst. Polit. Iasi, IV(VIII), Fasc. 3-4, 203 (1958)

13 Cr. I. Simionescu, St. Cercet. Şt. Chim., 10, 303 (1959)

14 Cr. I. Simionescu and N. Simionescu, St. Cercet. St. Chim., 12, 233 (1961)

15 Cr. I. Simionescu and E. Calistru, St. Cercet. Şt. Chim., 12, 227 (1961)

16 A. Cernătescu-Asandei and Cr. I. Simionescu, St. Cercet. SSt. Chim., 13, 129 (1962)

17 A. Cernătescu-Asandei, M. Grigoraş and Cr. I. Simionescu, Cellulose Chem. Technol., 2, 75 (1968), https://www.cellulosechemtechnol.ro/

18 Cr. I. Simionescu, E. Calistru, N. Simionescu and M. Hrihorov, St. Cercet. St. Chim., 12, 241 (1961)

19 Cr. I. Simionescu, Dokl. Akad. Nauk SSR Biol. Sci. Sect., 6, 434 (1962)

20 M. Grigoraş, N. Simionescu and Cr. I. Simionescu, St. Cercet. St. Chim., 3, 535 (1964)

21 M. Grigoraş, N. Simionescu and Cr. I. Simionescu, Rev. Roum. Chim., 9, $487 \quad$ (1964), http://revroum.lew.ro

${ }^{22}$ G. Cazacu, M. Capraru and V. I. Popa, in "Advances in Natural Polymers, Advanced Structured Materials", edited by S. Thomas et al., SpringerVerlag, Berlin, Heidelberg, 2013, Chapter 8, p. 255

23 D. Harman, J. Gerontol., 11, 298 (1956), https://doi.org/10.1093/geronj/11.3.298

24 I. Ignat, I. Volf and V. I. Popa, Food Chem., 126, 1821

(2011), https://doi.org/10.1016/j.foodchem.2010.12.026

25 I. Volf and V. I. Popa, "Biomass as Renewable Raw Material to Obtain Bioproducts of High-Tech Value", edited by Valentin Popa and Irina Volf, Elsevier, 2018, Chapter 4, p. 113

26 Cr. I. Simionescu, V. Rusan and V. I. Popa, Cellulose Chem. Technol., 21, 3 (1987), https://www.cellulosechemtechnol.ro/

27 O. C. Bujor, I. A. Talmaciu, I. Volf and V. I. Popa,

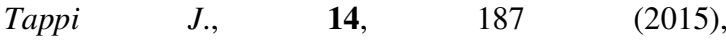
https://www.tappi.org/publications-standards/tappijournal/home/
28 V. I. Popa, in "Polysaccharides in Medicinal and Pharmaceutical Application", edited by Valentin I. Popa, Smithers, 2011, p. 57

29 V. I. Popa, in "Polymeric Biomaterials", edited by Valentin I. Popa, CRC Press/Taylor \& Francis, 2013, p. 709

A. R. Hainal, I. Ignat, I. Volf and V. I. Popa, Cellulose Chem. Technol., 45, 211 (2011). https://www.cellulosechemtechnol.ro/pdf/CCT34(2011)/p.211-219.pdf

31 A. R. Hainal, R. Diaconescu, I. Volf and V. I. Popa, Rom. Biotechnol. Lett., 17, 7084 (2012)

32 I. Ignat, D. G. Radu, I. Volf, A. I. Pag and V. I. Popa, Cellulose Chem. Technol., 47, 387 (2013), https://www.cellulosechemtechnol.ro/pdf/CCT56(2013)/p.387-399.pdf

33 C. Tanase, I. Volf, S. Vintu, R. Gradinaru and V. I. Popa, Cellulose Chem. Technol., 47, 553 (2013), https://www.cellulosechemtechnol.ro/pdf/CCT78(2013)/p.553-563.pdf

34 I. Volf, I. Ignat, M. Neamtu and V. I. Popa, Chem. Pap., 68, 121 (2014), https://doi.org/10.2478/s11696013-0417-6

35 C. Tanase, I. Boz, A. Stingu, I. Volf and V. I. Popa, Ind. Crop. Prod., 60, $160 \quad$ (2014), http://dx.doi.org/10.1016/j.indcrop.2014.05.039

36 R. E. Ghitescu, A. M. Popa, V. I. Popa, R. M. Rossi and G. Fortunato, Int. J. Pharm., 494, 278 (2015), http://dx.doi.org/10.1016/j.ijpharm.2015.08.020 03785173

37 R. E. Ghitescu, I. Volf, C. Carausu, A. M. Bühlmann, I. A. Gilca et al., Ultrason. Sonochem., 22, 535

(2015), http://dx.doi.org/10.1016/j.ultsonch.2014.07.013

38 A. I. Talmaciu, I. Volf and V. I. Popa, Chem. Biodivers., $\quad 12, \quad 1635 \quad$ (2015), https://doi.org/10.1002/cbdv.201400415

39 L. Lazar, A. I. Talmaciu, I. Volf and V. I. Popa, Ultrason. Sonochem., 32, $191 \quad$ (2016), http://dx.doi.org/10.1016/j.ultrasonch.2016.003.009

40 C. Tanase, I. Boz and V. I. Popa, Rom. Biotechnol. Lett., 21, $11238 \quad$ (2016), https://erepository.org/rbl/vol.21/iss.1/20.pdf

41 A. I. Talmaciu, M. Ravber, I. Volf, Z. Knez and V. I. Popa, J. Supercrit. Fluid., 117, 243 (2016), http://dx.doi.org/10.1016/j.supflu.2016.07.001

${ }^{42}$ C. Tanase, S. Oroian, S. L. Cosarca and V. I. Popa, Cellulose Chem. Technol., 50, 529 (2016), https://www.cellulosechemtechnol.ro/pdf/CCT56(2016)/p.529-534.pdf

43 R. E. Ghitescu, A. M. Popa, A. Schipanski, C. Hirsch, G. Yazgan et al., Eur. J. Pharm. Biopharm., 122, $78 \quad$ (2018), https://doi.org/10.1016/j.ejpb.2017.10.009

44 O. C. Bujor, C. Le Bourvellec, I. Volf, V. I. Popa and C. Dufour, Food Chem., 213, 58 (2016), http://dx.doi.org/10.1016/j.foodchem.2016.06.042 
45

Food Bujor, C. Giniès, V. I. Popa and C. Dufour, Food Chem., 252, $356 \quad$ (2018), https://doi.org/10.1016/j.foodchem.2018.01.052

46 C. Tanase, A. I. Talmaciu, C. I. Bara, I. Boz, I. Volf et al., BioResources, 13, 3994 (2018), https://bioresources.cnr.ncsu.edu/resources/newaspects-of-biomass-waste-valorization-spruce-barkcrude-extracts-as-plant-growth-regulators/
47 C. Tanase, L. Berta, A. Mare, A. Man, A. I. Talmaciu et al., Eur. J. Wood Wood Prod., 78, 281 (2020), https://doi.org/10.1007/s00107-020-01502-3

48 D. Jitaru (Ciobotariu), D. Ungureanu, M. Ciocoiu, M. Bădescu, V. I. Popa et al., Rev. Med. Chir. Soc. Med. Nat., Iaşi, 109, supl. nr. 1, 33 (2005)

49 M. Aviram, Eur. J. Clin. Chem. Clin. Biochem., 34, 599 (1996), https://pubmed.ncbi.nlm.nih.gov/8877334/ 